Acta Sci. Pol. Technol. Aliment. 19(2) 2020, 149-157

pISSN 1644-0730

eISSN 1898-9594

http://dx.doi.org/10.17306/J.AFS.2020.0773

ORIGINAL PAPER

Received: 13.02.2020

Accepted: 8.04.2020

\title{
THERMAL MODIFICATION OF HEN EGG WHITE LYSOZYME USING MICROWAVE TREATMENT
}

\author{
Tianyu Yang ${ }^{\bowtie}$, Grzegorz Leśnierowski \\ Food Quality and Safety Management, Food Science and Nutrition, Poznań University of Life Science \\ Wojska Polskiego 28, 60-637 Poznań, Poland
}

\begin{abstract}
Background. Thermal modification has commonly been used in the processing of chicken egg white lysozyme and has shown good antibacterial results in the field of laboratory study. However, the use of conventional thermal energy sources still presents disadvantages. In this work, microwave radiation was used as a new alternative to conventional sources of thermal energy for the modification of lysozyme.

Materials and methods. The material for modification was $5 \%$ concentration monomer lysozyme solutions with different $\mathrm{pH}$ levels. The enzyme was modified by microwave radiation under different microwave powers and different modification times separately. Important lysozyme protein parameters, such as: electrophoresis, hydrolytic activity, hydrophobicity, and solubility, were evaluated.

Results. Our research showed that the number of oligomers, especially dimers, and the surface hydrophobicity increased significantly in the preparations obtained after the processes under the appropriate conditions of modification. The highest production efficiency yield was $54.4 \%$ oligomers and $30.9 \%$ dimers. An additional beneficial effect of using this new method was the fact that the hydrolytic activity did not decrease as much as in the case of other thermal methods. And the solubility of the obtained preparations was high, ranging from $87 \%$ to $100 \%$.

Conclusion. The research showed that lysozyme dimer formation and other important protein properties changed effectively. Such a method not only changed the protein folding structure but also offered the advantages of a short processing time, high efficiency and easy enzyme control. It will have a greater application potential after further development.
\end{abstract}

Keywords: lysozyme, microwave modification, physicochemical properties, lysozyme oligomers

\section{INTRODUCTION}

Lysozyme (EC 3.2.1.17, N-acetylmuramic-hydrolase) is a type of enzyme that is widely found in organisms in nature. The most important property of lysozyme is its antibacterial activity (Ibrahim et al., 1994; Leśnierowski, 2015). However, the antibacterial activity against Gram-negative bacteria has a lower effectiveness than the activity against Gram-positive bacteria due to the more protective outer membrane structure of Gram-negative bacteria. Related research indicates that the antibacterial properties of lysozyme can be extended through significant changes in the structure of the lysozyme molecule by modification (Lesnierowski and Stangierski, 2018; Touch et al., 2004). Currently, several methods of lysozyme modification are known;

Funding: Poznań University of Life Sciences.

『yangtianyu0129@163.com, https://orcid.org/0000-0001-9658-4933 
among the most important methods are chemical, thermal, thermal-chemical and membrane techniques (Ibrahim, 1991; 1996a; Leśnierowski et al., 2009; Silva Freitas and Abrahão-Neto, 2010). But each of these methods also has disadvantages, such as significant irreversible denaturation of the protein, decrease in hydrolytic activity and limited solubility of preparations obtained after the modification (Choi et al., 2017; Ibrahim et al., 1996b). To date, it has not been possible to achieve a complete transformation of the natural enzyme into an oligomeric form with one hundred percent dimer content. Therefore, new ways to modify the enzyme and to use new energy sources for this modification are continuously under investigation.

Microwave radiation has commonly been used by scholars as a heating source in many scientific studies, and in many technological and chemical processes. It was found that the use of the microwave field in aqueous media is similar to a conventional heating method and could enhance proper biological activity (Rejasse et al., 2007). In addition, the microwave field could change the folding structure of proteins and expose more hydrophobic groups when using a microwave to accelerate the phosphorylation of egg white protein (Li et al., 2018).

Taking all of this into account, we decided that it is worth using these phenomena in the modification processes of chicken egg ingredients. The purpose of this work was to use microwave radiation to modify lysozyme isolated from chicken egg white. This paper presents the results of our preliminary studies on the effects of using microwave energy on the most important parameters of a modified enzyme, such as its oligomerization, hydrophobicity, activity and solubility of the obtained preparations.

\section{MATERIALS AND METHODS}

\section{Materials}

The material to be modified was lysozyme powder with a hydrolytic activity of $21252 \mathrm{U} / \mathrm{mg}$ isolated from hen egg white by the Belovo Company of Belgium.

\section{Procedure of lysozyme modification by microwave radiation}

The lysozyme monomer powder was dissolved in distilled water at a concentration of $5 \%$, and the $\mathrm{pH}$ was fixed at 4.0, 6.0 and 8.0 using $1 \mathrm{M} \mathrm{NaOH}$ or $1 \mathrm{M} \mathrm{HCl}$. A total of $2 \mathrm{~cm}^{3}$ of each sample was transferred to 50 $\mathrm{cm}^{3}$ containers that were tightly sealed. Each sample was prepared in 5 replicates. The samples were then placed in a microwave reactor and modified by microwave radiation under the following conditions: the microwave radiation generator used in the modification was a professional microwave reactor (Sharp, EU, model R-879-A).

- Microwave power: $\quad 270 \mathrm{~W}$ $450 \mathrm{~W}$

$630 \mathrm{~W}$

- Time of modification: 1 cycle (32 seconds)

$$
3 \text { cycles (96 seconds) }
$$

5 cycles (160 seconds)

The modified lysozyme was stored in a refrigerator at $5^{\circ} \mathrm{C}$ until the next phase of the experiment.

\section{Analytical procedure}

Electrophoresis. According to the methods of Laemmli (1970), the electrophoresis method on 6\% thickening polyacrylamide gel and $12.5 \%$ split polyacrylamide gel using a Hoefer Scientific Instruments SE-600 (San Francisco, USA) apparatus was used to assess oligomer formation.

After the electrophoresis, the gel was fixed for one hour in a solution consisting of $40 \%$ water, $50 \%$ methanol, and $10 \%$ acetic acid. The gel was then stained for $20 \mathrm{~h}$ in a $10 \%$ acetic acid solution with the addition of $0.25 \mathrm{~g}$ Coomassie Brilliant Blue R-250.

The gels were scanned and stored as computer files. Next, densitometric analysis was performed using TotalLab Quantity computer software by Nonlinear Dynamics Ltd. (United Kingdom, USA).

Hydrolytic activity of modified lysozymes. The hydrolytic activity of lysozyme was determined by the spectrophotometric method according to Parry et al. (1965). The enzyme activity is reflected in the absorbance reduction of the turbidity of the Micrococcus lysodeikticus bacterial suspension, which was measured at a wavelength of $450 \mathrm{~nm}$ using a Carl Zeiss Jena Stv. VSU-28 spectrophotometer (German), after adding lysozyme. The result is presented as the rate of 
the decrease in absorbance per min of the initial rate of reaction.

Hydrophobicity of modified lysozyme. The hydrophobicity of modified lysozyme was determined by the Lieskie method (Lieske and Konrad, 1994), with modifications according to Leśnierowski et al. (2005). The surface hydrophobicity of lysozyme was determined by measuring the absorbance at $\lambda=595 \mathrm{~nm}$ of two protein samples prepared simultaneously according to the ability of the polyoxyethylene sodium monooleate (Tween 80, SERVA, Germany) to bind hydrophobic sites of the proteins and the quantifiable dye complex.

Solubility of modified lysozyme. The solubility of modified lysozyme was tested spectrophotometrically according to the method approved by the American Association of Cereal Chemists (1976; Shen, 1976), where the degree of light transmittance in the solution was determined. The solubility ( $T$ - transmittance) was determined at a wavelength equal to $450 \mathrm{~nm}$, with an optical path length of $10 \mathrm{~mm}$, using the formula:

$$
T=\frac{I_{0}}{I} \cdot 100 \%
$$

where:

$I_{0}$ - absorbance of the solution before the modified lysozyme preparation was dissolved,

$I$ - absorbance of the solution after the modified lysozyme preparation was dissolved.

Statistical analysis. All determinations were performed with a minimum of five replicates. Statistical analysis was performed using Statistica v. 13.0 software. All data regarding the parameters tested were evaluated using linear regression analysis.

\section{RESULTS AND DISCUSSION}

The novelty of this research was the use of a new energy source to modify hen egg white lysozyme. The principle of this new method is to use high-frequency stimulation in order to heat the medium and increase the temperature of the lysozyme molecules (Huang et al., 2005). The advantages of a lower processing time and a reduction of the negative impact mean that it has potential application value (Rejasse et al., 2007). In this work, lysozyme was modified according to a previous procedure, including variable microwave radiation power, variable acidity of the environment, and variable modification time. As a result, the products obtained differ in oligomeric composition and physicochemical properties compared with the unmodified monomer. The analytical data obtained for all preparations produced after modification were collected in Table 1. Electropherograms illustrating changes in the fractional composition of the modified lysozyme molecules are shown in Figure 1.

The data of Table 1 indicates that the microwave modification produced very good and expected results. The number of oligomers increased significantly, accompanied by an increase in the higher surface hydrophobicity, and a decrease in the solubility. Depending on the modification conditions, the fraction of produced oligomers in the samples ranged from 5.7 to $54.4 \%$. The highest amount of dimer formation was between $20.4 \%$ and $30.9 \%$. Lysozyme usually contains $37-29 \%$ dimers after conventional thermal modification. That means the amount of dimer produced is comparable to or slightly higher than conventional thermal modification under certain conditions (Leśnierowski and Cegielska-Radziejewska, 2012). However, the composition of oligomers is related to a variety of factors, and the results span a large range. Further research is needed to determine the optimal conditions and a comprehensive comparison. The hydrophobicity of the modified lysozyme was also increased, and the value of sample 27 was the highest, reaching $53.5 \%$. As with other thermal modifications, the hydrolytic activity was only slightly diminished. The lowest hydrolytic activity drops to $7121 \mathrm{U} / \mathrm{mg}(34 \%)$.

To confirm the observed relationships, linear regression analysis of the data (Table 2) was also conducted.

The number of coefficients shows that all the factors, i.e. modification time, power and $\mathrm{pH}$ of the solution, had a significant effect on dimer formation. The standardized regression correlation coefficient of microwave power is 0.20 , which is much lower than those of the other factors $(0.63,0.67)$. A change in microwave power has less of an influence on the result compared with the other factors.

Figure 2 presenting the heating cycle and $\mathrm{pH}$ lead to greater changes in the value of each dependent 
Yang, T., Leśnierowski, G. (2020). Thermal modification of hen egg white lysozyme using microwave treatment. Acta Sci. Pol. Technol. Aliment., 19(2), 149-157. http://dx.doi.org/10.17306/J.AFS.2020.0773

Table 1. Characterization of lysozyme modified with combinations of microwave fields

\begin{tabular}{|c|c|c|c|c|c|c|c|c|c|}
\hline $\begin{array}{c}\text { Power of } \\
\text { micro- } \\
\text { wave } \\
\text { W }\end{array}$ & $\begin{array}{c}\text { Sample } \\
\text { no. }\end{array}$ & $\mathrm{pH}$ & $\begin{array}{l}\text { Time } \\
\text { cycle }\end{array}$ & $\begin{array}{l}\text { Dimer } \\
\%\end{array}$ & $\begin{array}{c}\text { Trimer } \\
\%\end{array}$ & $\begin{array}{c}\text { Total } \\
\text { oligomers } \\
\%\end{array}$ & $\begin{array}{c}\text { Retention } \\
\text { activity } \\
\%\end{array}$ & $\begin{array}{l}\text { Change in } \\
\text { hydropho- } \\
\text { bicity } \\
\%\end{array}$ & $\begin{array}{c}\text { Solubility } \\
\%\end{array}$ \\
\hline \multirow[t]{9}{*}{270} & 1 & 4 & $1(32 s)$ & $5.70 \pm 0.16$ & 0.0 & $5.70 \pm 0.16$ & $88 \% \pm 1.7 \%$ & $11.54 \pm 0.11$ & $100 \pm 0$ \\
\hline & 2 & & $3(96 s)$ & $8.90 \pm 0.16$ & 0.0 & $8.90 \pm 0.16$ & $80 \% \pm 1.3 \%$ & $13.82 \pm 0.15$ & $100 \pm 0$ \\
\hline & 3 & & $5(160 \mathrm{~s})$ & $20.44 \pm 0.11$ & $4.78 \pm 0.13$ & $25.22 \pm 0.24$ & $64 \% \pm 1.1 \%$ & $26.48 \pm 0.18$ & $100 \pm 0$ \\
\hline & 4 & 6 & $1(32 \mathrm{~s})$ & $13.18 \pm 0.15$ & $3.66 \pm 0.11$ & $16.84 \pm 0.26$ & $77 \% \pm 1.0 \%$ & $18.30 \pm 0.16$ & $98.20 \pm 0.23$ \\
\hline & 5 & & $3(96 \mathrm{~s})$ & $17.80 \pm 0.16$ & $6.94 \pm 0.11$ & $24.74 \pm 0.26$ & $62 \% \pm 1.0 \%$ & $25.70 \pm 0.1$ & $97.40 \pm 0.23$ \\
\hline & 6 & & $5(160 s)$ & $21.70 \pm 0.16$ & $10.72 \pm 0.15$ & $36.34 \pm 0.42$ & $57 \% \pm 1.1 \%$ & $35.82 \pm 0.13$ & $96.50 \pm 0.23$ \\
\hline & 7 & 8 & $1(32 \mathrm{~s})$ & $16.64 \pm 0.11$ & $9.14 \pm 0.11$ & $29.26 \pm 0.37$ & $66 \% \pm 1.0 \%$ & $28.66 \pm 0.11$ & $90.20 \pm 0.23$ \\
\hline & 8 & & $3(96 \mathrm{~s})$ & $22.40 \pm 0.16$ & $11.00 \pm 0.16$ & $38.50 \pm 0.33$ & $58 \% \pm 0.9 \%$ & $37.52 \pm 0.18$ & $89.40 \pm 0.23$ \\
\hline & 9 & & $5(160 \mathrm{~s})$ & $27.90 \pm 0.16$ & $12.08 \pm 0.13$ & $46.56 \pm 0.42$ & $50 \% \pm 4.9 \%$ & $43.36 \pm 0.11$ & $88.60 \pm 0.23$ \\
\hline \multirow[t]{9}{*}{450} & 10 & 4 & $1(32 \mathrm{~s})$ & $6.80 \pm 0.1$ & $2.32 \pm 0.08$ & $9.12 \pm 0.18$ & $82 \% \pm 0.7 \%$ & $12.16 \pm 0.09$ & $97.79 \pm 0.19$ \\
\hline & 11 & & $3(96 \mathrm{~s})$ & $9.12 \pm 0.13$ & $8.88 \pm 0.13$ & $18.00 \pm 0.25$ & $76 \% \pm 0.9 \%$ & $17.24 \pm 0.11$ & $97.51 \pm 0.23$ \\
\hline & 12 & & $5(160 s)$ & $21.80 \pm 0.16$ & $9.32 \pm 0.13$ & $31.12 \pm 0.29$ & $55 \% \pm 0.7 \%$ & $30.12 \pm 0.18$ & $97.22 \pm 0.23$ \\
\hline & 13 & 6 & $1(32 \mathrm{~s})$ & $13.82 \pm 0.08$ & $5.98 \pm 0.08$ & $23.90 \pm 0.22$ & $75 \% \pm 0.9 \%$ & $21.60 \pm 0.16$ & $96.82 \pm 0.23$ \\
\hline & 14 & & $3(96 \mathrm{~s})$ & $18.82 \pm 0.13$ & $8.42 \pm 0.13$ & $32.82 \pm 0.38$ & $65 \% \pm 0.8 \%$ & $30.82 \pm 0.18$ & $95.94 \pm 0.23$ \\
\hline & 15 & & $5(160 s)$ & $24.12 \pm 0.13$ & $11.92 \pm 0.13$ & $42.60 \pm 0.35$ & $46 \% \pm 0.7 \%$ & $40.68 \pm 0.18$ & $95.09 \pm 0.23$ \\
\hline & 16 & 8 & $1(32 \mathrm{~s})$ & $18.48 \pm 0.13$ & $9.28 \pm 0.13$ & $32.56 \pm 0.32$ & $64 \% \pm 1.1 \%$ & $31.18 \pm 0.15$ & $89.88 \pm 0.23$ \\
\hline & 17 & & $3(96 \mathrm{~s})$ & $18.60 \pm 5.39$ & $12.42 \pm 0.08$ & $37.52 \pm 5.37$ & $54 \% \pm 0.8 \%$ & $40.90 \pm 0.52$ & $89.13 \pm 0.23$ \\
\hline & 18 & & $5(160 s)$ & $28.80 \pm 0.16$ & $13.12 \pm 0.13$ & $49.98 \pm 0.37$ & $40 \% \pm 0.8 \%$ & $46.78 \pm 0.13$ & $88.13 \pm 0.23$ \\
\hline \multirow[t]{9}{*}{630} & 19 & 4 & $1(32 \mathrm{~s})$ & $5.68 \pm 0.08$ & $3.90 \pm 0.07$ & $11.08 \pm 0.19$ & $80 \% \pm 0.7 \%$ & $14.20 \pm 0.16$ & $97.10 \pm 0.23$ \\
\hline & 20 & & $3(96 \mathrm{~s})$ & $10.32 \pm 0.13$ & $7.50 \pm 0.07$ & $21.52 \pm 0.24$ & $72 \% \pm 1.1 \%$ & $20.18 \pm 0.13$ & $96.88 \pm 0.23$ \\
\hline & 21 & & $5(160 s)$ & $22.60 \pm 0.16$ & $12.24 \pm 0.09$ & $41.24 \pm 0.28$ & $52 \% \pm 0.8 \%$ & $40.12 \pm 0.18$ & $96.11 \pm 0.23$ \\
\hline & 22 & 6 & $1(32 \mathrm{~s})$ & $18.30 \pm 0.16$ & $9.20 \pm 0.07$ & $31.70 \pm 0.25$ & $70 \% \pm 0.9 \%$ & $29.9 \pm 0.16$ & $95.95 \pm 0.23$ \\
\hline & 23 & & $3(96 \mathrm{~s})$ & $22.78 \pm 0.13$ & $11.30 \pm 0.1$ & $39.82 \pm 0.33$ & $60 \% \pm 0.9 \%$ & $36.90 \pm 0.16$ & $94.78 \pm 0.23$ \\
\hline & 24 & & $5(160 s)$ & $27.14 \pm 0.15$ & $14.82 \pm 0.08$ & $48.86 \pm 0.33$ & $44 \% \pm 0.9 \%$ & $46.10 \pm 0.16$ & $93.72 \pm 0.23$ \\
\hline & 25 & 8 & $1(32 \mathrm{~s})$ & $21.6 \pm 0.16$ & $14.66 \pm 0.11$ & $43.04 \pm 0.34$ & $54 \% \pm 1.1 \%$ & $41.60 \pm 0.16$ & $89.64 \pm 0.23$ \\
\hline & 26 & & $3(96 \mathrm{~s})$ & $26.28 \pm 0.13$ & $14.34 \pm 0.11$ & $47.74 \pm 0.3$ & $42 \% \pm 0.8 \%$ & $45.88 \pm 0.13$ & $88.38 \pm 0.23$ \\
\hline & 27 & & $5(160 s)$ & $30.9 \pm 0.16$ & $15.92 \pm 0.13$ & $54.44 \pm 0.36$ & $34 \% \pm 0.9 \%$ & $53.50 \pm 0.16$ & $87.22 \pm 0.23$ \\
\hline
\end{tabular}




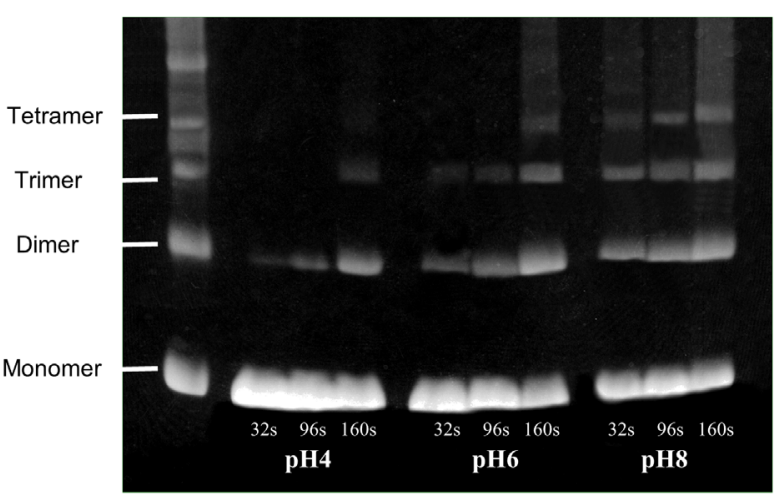

(A) $270 \mathrm{~W}$

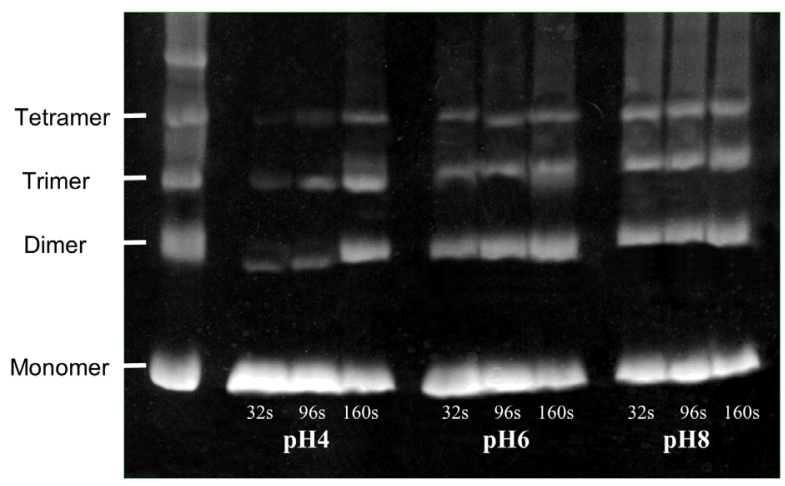

(C) $630 \mathrm{~W}$

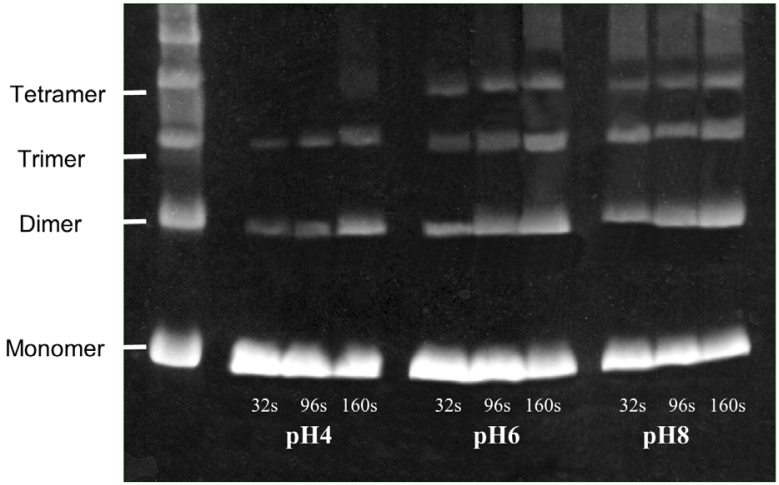

(B) $450 \mathrm{~W}$

Fig. 1. Electrophoretic images of lysozyme modified by microwave radiation: A-270 W microwave power, $\mathrm{B}-450 \mathrm{~W}$ microwave power, $\mathrm{C}-630 \mathrm{~W}$ microwave power

Table 2. Linear regression analysis for dependent variable Dimer formation

\begin{tabular}{lcccccc}
\hline & $b^{*}$ & Std. err. of $b^{*}$ & $b$ & Std. err. of $b$ & $t(131)$ & $p$-value \\
\hline Intercept & & & -11.23 & 1.12 & -10.00 & 0.00 \\
Power of microwave, W & 0.20 & 0.03 & 0.01 & 0.00 & 6.52 & 0.00 \\
$\mathrm{pH}$ & 0.63 & 0.03 & 2.78 & 0.13 & 21.14 & 0.00 \\
Time, cycle & 0.67 & 0.03 & 2.92 & 0.13 & 22.19 & 0.00 \\
\hline
\end{tabular}

$R=0.93930162, R^{2}=0.88228754$, adjusted $R^{2}=0.87959183$.

variable. An increasing trend of total oligomer formation appears, especially dimers, with an increase in different kinds of processing conditions.

Due to the structure changes of the lysozyme (Fig. 3) the hydrophobic groups hidden inside of the molecules are exposed on the surface, and hydrophobicity increases with the formation of more oligomers (Ibrahim et al., 1996b). Huang et al. (2005) considered two effects of microwaves on various enzymes. One of these effects is the heating effect produced by the movement of water molecules under the microwave, which can be heated to the target temperature in a short time, thus reducing enzyme degeneration during processing. The other effect is the non-thermal effect. Microwave energy regulates the configuration of enzyme molecules by accelerating molecular rotation, electron 
Yang, T., Leśnierowski, G. (2020). Thermal modification of hen egg white lysozyme using microwave treatment. Acta Sci. Pol. Technol. Aliment., 19(2), 149-157. http://dx.doi.org/10.17306/J.AFS.2020.0773
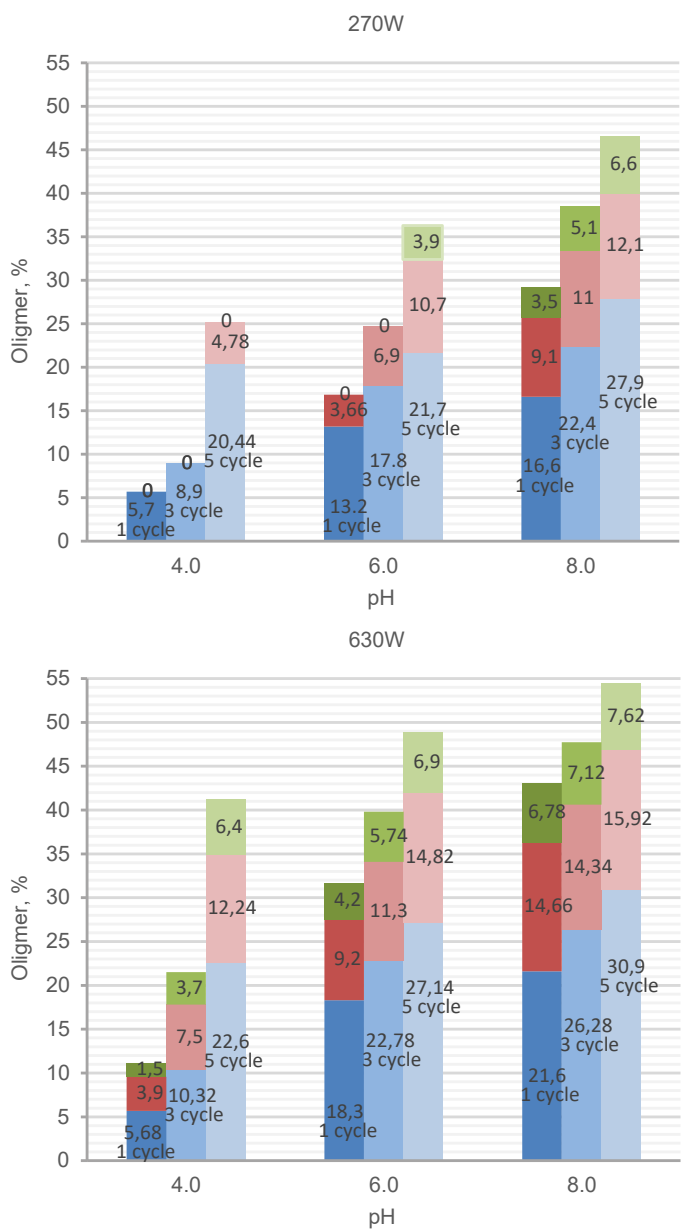

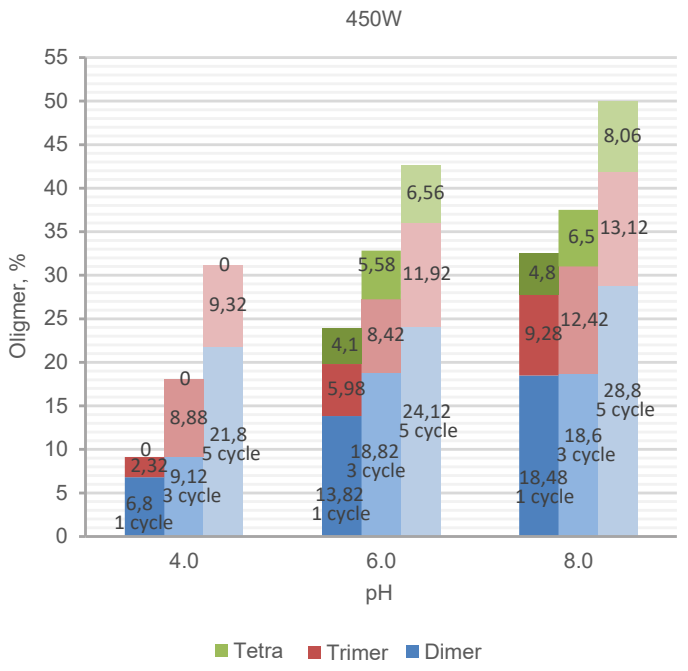

Fig. 2. The content of different oligomers according to different $\mathrm{pH}$ values, treatment times, and microwave power levels

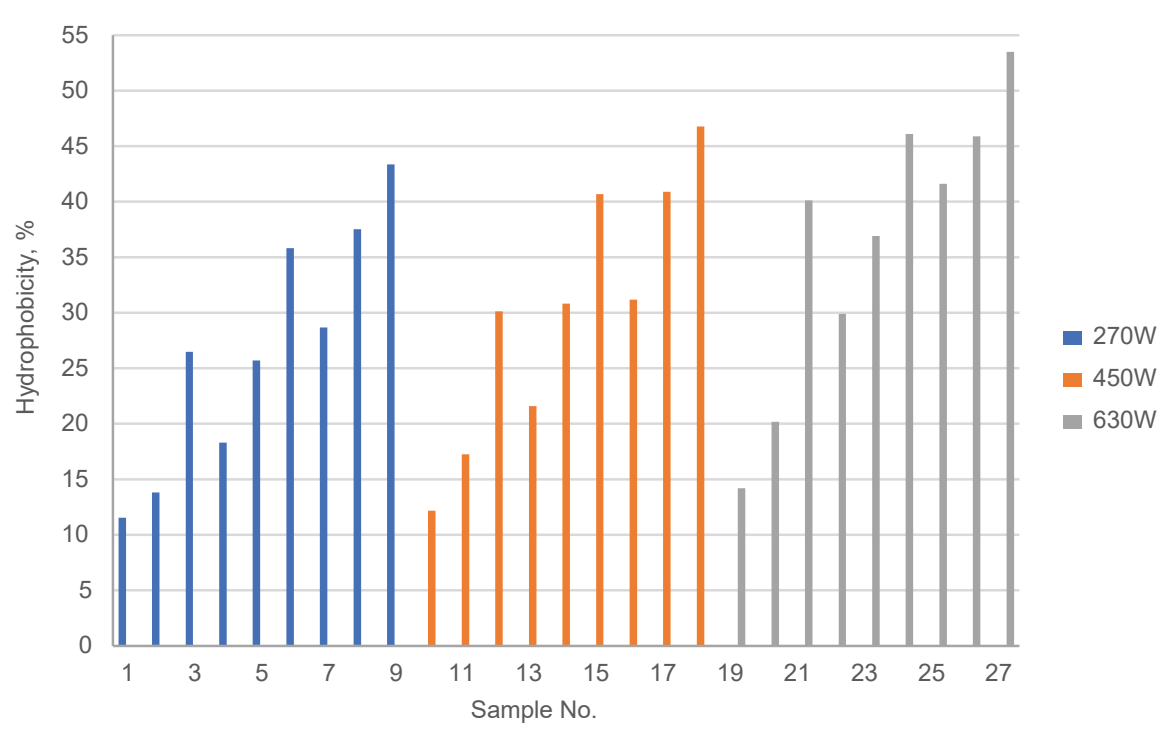

Fig. 3. The content of hydrophobicity according to different $\mathrm{pH}$ values, treatment times, and microwave power levels. The condition of the sample number is shown in Table 1 
spin, and oscillations in the catalytic region of the enzyme.

In contrast, the solubility of the modified lysozyme decreased with the degree of modification. The experiment carried out by Ibrahim also indicated that the modification process affects the solubility of lysozyme (Ibrahim et al., 1996b). We found that $\mathrm{pH}$ has a greater influence on the solubility in this process. Acidic conditions make the modified lysozyme readily soluble. In this study, a $\mathrm{pH}$ of 4 played a more important role in maintaining the solubility observed among most other factor changes, as a solubility of $96.1-100 \%$ was maintained. Lysozymes with a lower solubility became a hindrance to the operation and the measurement of their subsequent properties. Therefore, solubility is one of the most important parameters for lysozyme modification. It should be emphasized that in the presented microwave method of lysozyme modification, the obtained preparations were characterized by a significantly higher solubility in comparison with the preparations obtained by conventional thermal methods, such as the more than $80-95 \%$ solubility of conventional thermal methods (Ibrahim, 1998; Venkataramani et al., 2013). This property is the primary advantage of the microwave method and affects the superiority of this method over others.

Another important parameter of both unmodified and modified lysozyme is its hydrolytic activity. This enzyme activity, like solubility, was also damaged with a greater modification degree. However, the hydrolytic activity of the lysozyme produced by the new method decreased from the control simple from $21252 \mathrm{U} / \mathrm{mg}$ to $7121-18695 \mathrm{U} / \mathrm{mg}$, while maintaining a hydrolytic activity of $33-87 \%$, which is higher than thermal methods (maintained activity of $28-40 \%$; Leśnierowski, 2001), and membrane methods (maintained activity of $18.2-48.8 \% \mathrm{U} / \mathrm{mg}$; Leśnierowski et al., 2009). These phenomena of hydrolytic activity loss after modification have also been discovered by other researchers (Ibrahim et al., 1996a; Vilcacundo et al., 2018). The phenomena did not affect the bactericidal activity against Gram-positive bacteria. Inactivation of lysozyme also exerts a stronger inhibitory effect on some Gram-positive bacteria (Ibrahim et al., 2001; Carrillo and Ramos, 2018). However, the effect of the modification is a new activity directed against gram-positive and gram-negative bacteria, and this novel activity consists of the remaining part of the hydrolytic activity and completely new activity (Ibrahim et al., 1996b; Cegielska-Radziejewska et al., 2014). It is impossible to determine what process of catalytic activity contributes to the antibacterial effect due to the change in the conformation of the lysozyme molecule during the modification process (Ibrahim et al., 1996b). Maintaining hydrolytic activity was found to have antibacterial effects under some conditions, such as pressure (Masschalck et al., 2001).

So far, dimeric lysozyme, as a major antibacterial substance, was shown to limit bacteria by changing the bacterial permeability (Ibrahim et al., 1996a; 1996b). Ibrahim (1996b, 1998) suggested that the hydrophobicity and new antimicrobial properties of lysozyme are positively related. Previous research data show that a higher hydrophobicity of lysozyme has more new bactericidal activities. Therefore, although we have not shown the results of antibacterial tests here (there will be a separate study), we can infer that the use of microwave modification should significantly improve the antibacterial activity of lysozyme compared with previous results, especially with respect to the functional effect against Gram-negative bacteria, by increasing hydrophobicity and dimer content.

Ultimately, we can state that the microwave modification method can induce the formation of a high amount of lysozyme oligomers, especially a large number of dimer and increases of hydrophobicity. This process of change was positively correlated with processing time, $\mathrm{pH}$, and microwave power. However, it should be considered that decreases in solubility and activity are still side effects of this method. Further experiments to explore suitable modification conditions are needed.

\section{CONCLUSION}

The results of this study indicate that microwave radiation can induce a greater extent of oligomer lysozyme formation. A large amount of dimeric lysozyme was also obtained after modification with hydrophobicity and residual hydrolytic activity positively increasing. The solubility of modified lysozyme can be maintained at $100 \%$ under suitable conditions, which has a great impact on both application and research. However, the conditions of the microwave field method still have 
the potential to be improved and enhanced. Therefore, it is also necessary to study the new activity of modified lysozyme, especially its effects on Gram-negative bacteria. Further experiments are needed to optimize the level of solubility. Such research is also already being carried out by our group and will be reported after completion.

\section{REFERENCES}

Carrillo, W., Ramos, M. (2018). Identification of antimicrobial peptides of native and heated hydrolysates from hen egg white lysozyme. J. Med. Food, 21(9), 915-926. https://doi.org/10.1089/jmf.2017.0132

Cegielska-Radziejewska, R., Szablewski, T. (2014). Inhibition of food-borne bacteria by thermo-chemically modified egg white lysozyme. Afr. J. Microbiol. Res., 8, 6, 590-597. https://doi.org/10.5897/AJMR2013.6224

Choi, S., Attri, P., Lee, I., Oh, J., Yun, J. H., Park, J. H., ..., Lee, W. (2017). Structural and functional analysis of lysozyme after treatment with dielectric barrier discharge plasma and atmospheric pressure plasma jet. Sci. Rep., 7, 1027. https://doi.org/10.1038/s41598-01701030-w

Huang, W., Xia, Y. M., Gao, H., Fang, Y. J., Wang, Y., Fang, Y. (2005). Enzymatic esterification between $n$-alcohol homologs and $n$-caprylic acid in non-aqueous medium under microwave irradiation. J. Mol. Catal. B, Enzymatic, 35(4-6), 113-116. https://doi.org/10.1016/j.molcatb.2005.06.004

Ibrahim, H. R. (1998). On the novel catalytically-independent antimicrobial function of hen egg-white lyozyme: a conformation-dependent activity. Nahrung, 42(3-4), 187-193.

Ibrahim, H. R., Higashiguchi, S., Juneja, L. R., Kim, M., Yamamoto, T. (1996a). A structural phase of heat-denatured lysozyme with novel antimicrobial action. J. Agric. Food Chem., 44(6), 1416-1423. https://doi.org/10.1021/ jf9507147

Ibrahim, H. R., Higashiguchi, S., Koketsu, M., Juneja, L. R., Kim M., Yamamoto, T., Sugimoto, Y., Aoki, T. (1996b). Partially unfolded lysozyme at neutral $\mathrm{pH}$ agglutinates and kills Gram-negative and Gram-positive bacteria through membrane damage mechanism. J. Agric. Food Chem., 44(12), 3799-3806. https://dor.org/10.1021/ jf960133x

Ibrahim, H. R., Kato, A., Kobayashi, K. (1991). Antimicrobial effects of lysozyme against Gram-negative bacteria due to covalent binding of palmitic acid. J. Agric. Food
Chem., 39(11), 2077-2082. https://doi.org/10.1021/jf $00011 \mathrm{a} 039$

Ibrahim, H. R., Matsuzaki, T., Aoki, T. (2001). Genetic evidence that antibacterial activity of lysozyme is independent of its catalytic function. FEBS Lett., 506, 27-32. https://doi.org/10.1016/S0014-5793(01)02872-1

Ibrahim, H. R., Yamada, M., Matsushita, K., Kobayashi, K., Kato, A. (1994). Enhanced bactericidal action of lysozyme to Escherichia coli by inserting a hydrophobic pentapeptide into its C terminus. J. Biol. Chem., 269(7), 5059-5063.

Laemmli, U. K. (1970). Cleavage of structural proteins during the assembly of the head of bacteriophage T4. Nature, 227, 680-687.

Leśnierowski, G. (2001). Antibacterial activity of thermally modified lysozyme. EJPAU, 4(2). Retrieved from http:// www.ejpau.media.pl/volume4/issue2/food/art-17.html

Leśnierowski, G. (2015). Lysozyme and its modified forms: properties, potential for its production and application. In R. R. Watson, F. de Meester (Ed.), Handbook of eggs in human function (pp. 483-495). The Netherlands: Wageningen Acad. Publ.

Leśnierowski, G., Cegielska-Radziejewska, R. (2012). Potential possibilities of production, modification and practical application of lysozyme. Acta Sci. Pol., Technol. Aliment., 11(3), 223-230.

Leśnierowski, G., Kijowski, J., Cegielska-Radziejewska, R. (2009). Ultrafiltration-modified chicken egg white lysozyme and its antibacterial action. Int. J. Food Sci. Technol., 44(2), 305-311. http://doi.wiley.com/10.1111/ j.1365-2621.2008.01713.x

Leśnierowski, G., Konieczny, P., Kijowski, J. (2005). Proceedings of the XVII European Symposium on the Quality of Poultry Meat and XI European Symposium on the Quality of Eggs and Egg Products, 23-26 May 2005 (pp. 207-213). Golden Tulip Parkhotel Doorwerth, Doorwerth, Netherlands.

Lesnierowski, G., Stangierski, J. (2018). What's new in chicken egg research and technology for human health promotion? - A review. Trends Food Sci. Technol., 71(November 2017), 46-51. https://doi.org/10.1016/j. tifs.2017.10.022

Li, P., Sun, Z., Ma, M., Jin, Y., Sheng, L. (2018). Effect of microwave-assisted phosphorylation modification on the structural and foaming properties of egg white powder. LWT, 97, 151-156. https://doi.org/10.1016/j. lwt.2018.06.055

Lieske, B., Konrad, G. (1994). A new approach to estimate surface hydrophobicity of proteins. Milchwissenschaft, 49(12), 4. 
Masschalck, B., Van Houdt, R., Van Haver, E. G., Michiels, C. W. (2001). Inactivation of Gram-negative bacteria by lysozyme, denatured lysozyme, and lysozyme-derived peptides under high hydrostatic pressure, Appl. Environ. Microbiol., 67(1), 339-344. http://doi.org/10.1128/ AEM.67.1.339-344.2001

Parry, R. M. Jr, Chandan, R. C., Shahani, K. M. (1965). A rapid and sensitive assay of muramidase. Proc. Soc. Exp. Biol. Med. 119(2), 384-386.

Rejasse, B., Lamare, S., Legoy, M. D., Besson, T. (2007). Influence of microwave irradiation on enzymatic properties: applications in enzyme chemistry. J. Enzym. Inhib. Med. Chem., 22(5), 519-527. https://doi. org/10.1080/14756360701424959

Shen, J. L. (1976). Soy protein solubility: The effect of experimental conditions on the solubility of soy protein isolates. Cereal Chem., 53(6), 902-909.

Silva Freitas, D., Abrahão-Neto, J. (2010). Biochemical and biophysical characterization of lysozyme modified by PEGylation. Int. J. Pharm., 392(1-2), 111-117. https:// doi.org/10.1016/j.ijpharm.2010.03.036
Touch, V., Hayakawa, S., Saitoh, K. (2004). Relationships between conformational changes and antimicrobial activity of lysozyme upon reduction of its disulfide bonds. Food Chem., 84(3), 421-428. https://doi.org/10.1016/ S0308-8146(03)00252-8

Vilcacundo, R., Méndez, P., Reyes, W., Romero, H., Pinto, A., Carrillo, W. (2018). Antibacterial activity of hen egg white lysozyme denatured by thermal and chemical treatments. Sci. Pharm., 86(4), 48. https://doi. org/10.3390/scipharm86040048

Venkataramani, S., Truntzer, J., Coleman, D. R. (2013). Thermal stability of high concentration lysozyme across varying $\mathrm{pH}$ : A fourier transform infrared study. J. Pharm. Bioall. Sci., 5(2), 148. https://doi.org/10.4103/09757406.111821 